\title{
ON THE POTENTIAL USE OF INDEX PATHS FOR AVALANCHE ASSESSMENT
}

\author{
By A. Judson \\ (Rocky Mountain Forest and Range Experiment Station, 240 West Prospect Street, Fort Collins, \\ Colorado 80526, U.S.A.)
}

\begin{abstract}
Aвstract. The possible use of index paths to assess avalanche potential in large avalanche samples was evaluated with probability theory on 56 uncontrolled avalanche paths in Colorado. Results showed the technique yields limited information of little diagnostic value because of low conditional probabilities of joint occurrence and high yearly variance. $90 \%$ of pairs tested had probabilities $\leqq 0.20$ for a six-year period. Implications for researchers and field personnel are discussed.
\end{abstract}

RÉSumÉ. Sur la possibilité d'utiliser des couloirs témoins pour la prévision des avalanches. On a èvalue la possibilité d'utiliser des couloirs témoins pour prévoir le risque d'avalanches sur de vastes zones en appliquant la théorie des probabilités à 56 couloirs non observés dans le Colorado. Les résultats ont montré que cette technique donne des informations limitées de faible valeur de diagnostic à cause des faibles probabilités de coïncidence d'occurence et la forte variabilité inter-annuelle. $90 \%$ des paires étudiées ont des probabilités inférieures ou égales à 0,20 pour une période de 6 ans. On discute les conséquences de ces faits pour les chercheurs et le personnel de terrain.

ZuSAmmenfassung. Über die Möglichkeiten der Benutzung von Leitbahnen für die Lawinenvorhersage. Die Möglichkeit. Leitbahnen von Lawinen zur Vorhersage des Lawinenabgangs in einem grossen Gebiet zu benutzen, wurde mit Hilfe der Wahrscheinlichkeitstheorie an 50 unüberwachten Lawinenbahnen in Colorado untersucht. Die Ergebnisse lieferten nur eine beschränkte Information von geringem diagnostischem Wert, da sich die bedingte Wahrscheinlichkeit für einen gemeinsamen Abgang als gering und die jährliche Schwankung als hoch erwiesen. 90\% der untersuchten Paare hatten Wahrscheinlichkeiten von weniger als 0,20 in einer Periode von 6 Jahren. Die Folgerungen für Lawinenforscher und Feldpersonal werden diskutiert.

\section{INTRODUCTION}

The ability to make final snow-stability inferences from carefully interpreted information from observed avalanches is a fine art practiced by experienced forecasters. The technique is premised on the concept that presence of a fresh avalanche telegraphs the likelihood of additional events on nearby slopes of the same form and exposure. With this reasoning, forecasters have postulated that an event on a key or index path might provide warning of avalanches at certain other areas in a systematic manner. Some forecasters have used the technique in varying degrees to make snow safety decisions and stability evaluations for snow conditions over large areas based on better-known conditions in smaller areas. Success of the technique is unknown, but the location of a few reliable index paths in a mountain region would simplify wide-area forecasts and minimize uncertainties faced by practicing forecasters and research personnel.

An extension of this concept applies to model development. For example, the processoriented model developed by Judson and others (1980) used fixed terrain parameters for avalanche simulation over a small area in central Colorado. Expansion of this model to larger areas in multiform terrain presents intractable complications which have limited model use outside the initial test site.

The thrust of this study was to determine if a small number of select paths could be used to index avalanche response in large samples. 


\section{DATA}

Avalanche occurence data from 284 uncontrolled paths in northern and southern Colorado were used for the study. The northern mountain sample included 165 paths located in a $200 \mathrm{~km}^{2}$ area of the Front Range, while the southern mountain sample comprised 119 paths along and adjacent to U.S. Highway 550 in the San Juan Mountains; the area of this sample was also $200 \mathrm{~km}^{2}$. The samples include avalanche paths with a wide variety of topographic features located on all aspects. It should be emphasized that avalanche paths are not standard units, and what constitutes a single path for one person is perceived as several paths by another. Therefore. some paths are well-defined, small units, while others contain clusters of small units within a large area. Starting zone areas varied from less than one to 150 ha.

Data span two six-year periods, 1971-1977 for the San Juan Mountains and 1974-1980 for the Front Range. Records were taken by the University of Colorado (Armstrong and Ives. 1976) and by the U.S. Forest Service (Judson, unpublished), respectively. The Forest Service avalanche classification was used on both samples (Judson, 1970) by daily patrols. Observers were exceptionally well trained, had more than ten years' experience, were highly motivated, and had good access; avalanches were observed from a highway and on skis in the southern sample and from highways, skis, and over-snow vehicles in the northern area. When an observer was unsure as to which day an avalanche ran a judgment was made on the basis of textural characteristics of the avalanche debris in question, compared with other avalanche debris where the time was known. All things considered, timing was accurate to within $12 \mathrm{~h}$ in all but a few cases. The combined sample is the best set of natural avalanche data in the United States.

Both areas have continental climates with midwinter study-plot snow depths of from 1 to $2 \mathrm{~m}$; dry-snow avalanches are dominant. The study was limited to slab avalanches traveling more than $50 \mathrm{~m}$ slope distance on paths with ten or more avalanche days over the six-year period. 56, or one in five, of the 284 paths met these criteria. The avalanche-day concept developed by Obled (1970) consists of a day when one or more events are observed in a given area. For our study, the concept was applied to individual avalanche paths.

\section{METHOD}

Index potential of each of the 56 paths was tested using probability theory. Avalanche paths were ranked by avalanche days, then paired with every other path. Joint events were counted when avalanches on paired paths fell on the same calendar day. If $A_{i}$ and $A_{j}$ are two avalanche paths in a pair, then $P\left[A_{i} \mid A_{j}\right]$ is the conditional probability $A_{i}$ occurs given $A_{j}$ occurred, and $P\left[A_{j} \mid A_{i}\right]$ the conditional probability $A_{j}$ occurs given $A_{i}$ occurred. The number of days when avalanches can occur varies on almost every path depending on precipitation, snow depth. deposition and erosion patterns, the radiation balance, snow texture and structure, surface roughness, slope, and other physical features. Inasmuch as a definitive criterion for this variable was lacking, the number of potential avalanche days on each avalanche path was approximated by counting the days between the first and last event on each path over the six-year interval. Furthermore, all computations between pairs were based on the number of potential avalanche days given by the path with the longest potential avalanche season. Thus, if the potential number of avalanche days for two paired paths were 242 and 209 respectively, the period encompassed by the 242 days served as the base value for counting avalanche events for both paths.

Conditional probabilities for 35 pairs of avalanche paths in the northern mountains and 21 
pairs in the southern mountains were computed for individual years and for the six-year interval. An arbitrary probability of 0.40 was set as a minimum level for index potential of any pair $\left.P\left|A_{i}\right| A_{j}\right]$ and $P\left[A_{j} \mid A_{i}\right]$ because a higher value is inconsistent with this natural phenomenon and a lower one gives no assurance of real index potential.

\section{RESUlts}

Just one pair met the 0.40 criterion every year, and only 7 of the 805 pairs achieved this level for the six-year average. $90 \%$ of the pairs had six-year average conditional probabilities $\leqq 0.20$. The results came as a surprise because many of the pairs were physically similar and were situated side-by-side. Because it was suspected that groups of physically similar paths in close proximity might yield better results, five avalanche areas in the northern mountains, consisting of two large paths and three sets of combined paths, were paired in ten combinations. Of this group three pairs had conditional probabilities of joint occurrence $\geqq 0.40$ every year and six pairs equaled or exceeded 0.40 for the six-year interval. Several additional groups were tested by hand tabulations with poor results. Further computations for groups and individual pairs were made using a two-day time interval with essentially the same results. Lack of data limited group testing to the northern sample. Pairs with the highest conditional probabilities are shown in Table I. Yearly conditional probabilities varied from zero to 1.0 on most paths. Probabilities among highfrequency paths were no greater than those among low-frequency paths. As might be expected. low-frequency paths indexed the more active paths best.

TABle I. AVAlanche PATHS With THE highest CONDITIONAL PROBABILITY OF JOINT OCCURRENCE

\begin{tabular}{|c|c|c|c|c|c|c|c|c|c|c|}
\hline \multirow{2}{*}{$\begin{array}{l}\text { Pair } \\
\text { rank }\end{array}$} & \multicolumn{2}{|c|}{ 6-year period } & \multirow{2}{*}{$\begin{array}{l}\text { Years } \\
\text { with } \\
\text { joint } \\
\text { events }\end{array}$} & \multirow{2}{*}{$\begin{array}{l}\text { Joint } \\
\text { events }\end{array}$} & \multicolumn{2}{|c|}{$\begin{array}{c}\text { Avalanche } \\
\text { days }\end{array}$} & \multicolumn{2}{|c|}{ Annual range } & \multicolumn{2}{|c|}{$\begin{array}{c}\text { Potential } \\
\text { avalanche } \\
\text { days }\end{array}$} \\
\hline & $P\left[A_{i} \mid A_{j}\right]$ & $P\left[A_{j} \mid A_{i}\right]$ & & & $A_{i}$ & $A_{j}$ & $P\left[A_{i} \mid A_{j}\right]$ & $P\left[A_{j} \mid A_{i}\right]$ & $A_{i}$ & $A_{j}$ \\
\hline \multicolumn{11}{|c|}{ Northern mountains } \\
\hline $1 / 2$ & 0.74 & 0.55 & 6 & 59 & 107 & 80 & $0.62-1.00$ & $0.40-0.68$ & 242 & 209 \\
\hline $2 / 3$ & 0.68 & 0.49 & 6 & 39 & 80 & 57 & $0.50-0.89$ & $0.29-0.86$ & 209 & 212 \\
\hline $10 / 13$ & 0.48 & 0.40 & 5 & 10 & 25 & 21 & $0.00-0.75$ & $0.33-0.50$ & 208 & 189 \\
\hline $1 / 3$ & 0.74 & 0.39 & 6 & 42 & 107 & 57 & $0.60-0.86$ & $0.20-0.67$ & 242 & 212 \\
\hline $18 / 28$ & 0.55 & 0.43 & 5 & 6 & 14 & 11 & $0.00-1.00$ & $0.00-1.00$ & 184 & 113 \\
\hline $7 / 13$ & 0.43 & 0.35 & 4 & 9 & 26 & 21 & $0.00-1.00$ & $0.00-0.50$ & 175 & 189 \\
\hline $23 / 28$ & 0.36 & 0.33 & 3 & 4 & 12 & 11 & $0.00-1.00$ & $0.00-0.50$ & 174 & 113 \\
\hline $1 / 5$ & 0.77 & 0.32 & 6 & 34 & 107 & 44 & $0.67-1.00$ & $0.08-0.47$ & 242 & 234 \\
\hline $2 / 5$ & 0.57 & 0.32 & 6 & 25 & 79 & 44 & $0.33-1.00$ & $0.25-0.50$ & 209 & 234 \\
\hline $3 / 5$ & 0.41 & 0.32 & 6 & 18 & 56 & 44 & $0.20-1.00$ & $0.14-0.45$ & 212 & 234 \\
\hline $31 / 32$ & 0.30 & 0.33 & 3 & 3 & 9 & 10 & $0.00-1.00$ & $0.00-1.00$ & 101 & 102 \\
\hline $6 / 7$ & 0.37 & 0.29 & 4 & 10 & 34 & 27 & $0.00-0.57$ & $0.00-0.67$ & 190 & 175 \\
\hline $4 / 14$ & 0.65 & 0.27 & 6 & 13 & 49 & 20 & $0.50-1.00$ & $0.14-0.50$ & 192 & 151 \\
\hline $8 / 29$ & 0.64 & 0.27 & 5 & 7 & 26 & 11 & $0.00-1.00$ & $0.00-0.40$ & 177 & 125 \\
\hline $29 / 35$ & 0.38 & 0.27 & 3 & 3 & 11 & 8 & $0.00-1.00$ & $0.00-1.00$ & 125 & 121 \\
\hline $25 / 32$ & 0.30 & 0.27 & 3 & 3 & 11 & 10 & $0.00-0.50$ & $0.00-1.00$ & 181 & 102 \\
\hline $27 / 29$ & 0.30 & 0.27 & 3 & 3 & 11 & 10 & $0.00-1.00$ & $0.00-1.00$ & 194 & 125 \\
\hline $6 / 10$ & 0.36 & 0.26 & 6 & 9 & 34 & 25 & $0.17-0.67$ & $0.17-0.33$ & 190 & 208 \\
\hline $14 / 16$ & 0.26 & 0.26 & 3 & 5 & 19 & 19 & $0.00-0.50$ & $0.00-0.67$ & 151 & 163 \\
\hline $2 / 6$ & 0.59 & 0.25 & 6 & 20 & 80 & 34 & $0.33-0.83$ & $0.08-0.50$ & 209 & 190 \\
\hline
\end{tabular}


TABLE I. cont.

\begin{tabular}{|c|c|c|c|c|c|c|c|c|c|c|}
\hline \multirow{2}{*}{$\begin{array}{l}\text { Pair } \\
\text { rank }\end{array}$} & \multicolumn{2}{|c|}{ 6-year period } & \multirow{2}{*}{$\begin{array}{l}\text { Years } \\
\text { with } \\
\text { joint } \\
\text { events }\end{array}$} & \multirow{2}{*}{$\begin{array}{l}\text { Joint } \\
\text { events }\end{array}$} & \multicolumn{2}{|c|}{$\begin{array}{c}\text { Avalanche } \\
\text { days }\end{array}$} & \multicolumn{2}{|c|}{ Annual range } & \multicolumn{2}{|c|}{$\begin{array}{c}\text { Potential } \\
\text { avalanche } \\
\text { days }\end{array}$} \\
\hline & $P\left[A_{i} \mid A_{j}\right]$ & $P\left[A_{j} \mid A_{i}\right]$ & & & $A_{i}$ & $A_{j}$ & $P\left[A_{i} \mid A_{j}\right]$ & $P\left[A_{j} \mid A_{i}\right]$ & $A_{i}$ & $A_{j}$ \\
\hline \multicolumn{11}{|c|}{ Southern mountains } \\
\hline $12 / 16$ & 0.55 & 0.50 & 4 & 6 & 12 & 11 & $0.00-1.00$ & $0.00-1.00$ & 145 & 71 \\
\hline $12 / 14$ & 0.45 & 0.42 & 3 & 5 & 12 & 11 & $0.00-0.50$ & $0.00-1.00$ & 142 & 98 \\
\hline $5 / 8$ & 0.46 & 0.40 & 5 & 6 & 16 & 13 & $0.00-1.00$ & $0.00-1.00$ & 182 & 199 \\
\hline $5 / 21$ & 0.67 & 0.38 & 4 & 6 & 16 & 9 & $0.00-1.00$ & $0.00-0.75$ & 182 & 162 \\
\hline $1 / 2$ & 0.52 & 0.38 & 5 & 11 & 29 & 21 & $0.00-0.70$ & $0.25-0.50$ & 181 & 116 \\
\hline $14 / 15$ & 0.36 & 0.40 & 3 & 4 & 10 & 11 & $0.00-1.00$ & $0.00-0.67$ & 99 & 166 \\
\hline $14 / 16$ & 0.36 & 0.36 & 3 & 4 & 11 & 11 & $0.00-1.00$ & $0.00-0.50$ & 98 & 71 \\
\hline $16 / 20$ & 0.36 & 0.36 & 3 & 4 & 11 & 11 & $0.00-1.00$ & $0.00-0.67$ & 71 & 106 \\
\hline $6 / 14$ & 0.50 & 0.33 & 3 & 5 & 15 & 10 & $0.00-0.67$ & $0.00-1.00$ & 174 & 98 \\
\hline $12 / 13$ & 0.36 & 0.33 & 2 & 4 & 12 & 11 & $0.00-0.50$ & $0.00-1.00$ & 145 & 145 \\
\hline $12 / 17$ & 0.36 & 0.33 & 2 & 4 & 12 & 11 & $0.00-0.60$ & $0.00-0.50$ & 145 & 177 \\
\hline $12 / 20$ & 0.36 & 0.33 & 3 & 4 & 12 & 11 & $0.00-1.00$ & $0.00-1.00$ & 145 & 106 \\
\hline $11 / 12$ & 0.33 & 0.33 & 2 & 4 & 12 & 12 & $0.00-1.00$ & $0.00-0.50$ & 179 & 145 \\
\hline $2 / 06$ & 0.40 & 0.30 & 3 & 6 & 20 & 15 & $0.00-1.00$ & $0.00-1.00$ & 116 & 174 \\
\hline $8 / 21$ & 0.50 & 0.31 & 4 & 4 & 13 & 8 & $0.00-1.00$ & $0.00-1.00$ & 199 & 162 \\
\hline $5 / 07$ & 0.36 & 0.31 & 3 & 5 & 16 & 14 & $0.00-1.00$ & $0.00-1.00$ & 182 & 153 \\
\hline $8 / 20$ & 0.36 & 0.31 & 2 & 4 & 13 & 11 & $0.00-0.60$ & $0.00-0.50$ & 199 & 106 \\
\hline $7 / 21$ & 0.40 & 0.29 & 3 & 4 & 14 & 10 & $0.00-0.50$ & $0.00-0.50$ & 153 & 162 \\
\hline $7 / 13$ & 0.36 & 0.29 & 2 & 4 & 14 & 11 & $0.00-0.50$ & $0.00-0.60$ & 153 & 145 \\
\hline $6 / 15$ & 0.36 & 0.27 & 3 & 4 & 15 & 11 & $0.00-1.00$ & $0.00-1.00$ & 174 & 166 \\
\hline \multicolumn{11}{|c|}{ Groups - Northern mountains } \\
\hline $\mathrm{A} / \mathrm{B}$ & 0.71 & 0.55 & 6 & 59 & 107 & 83 & $0.67-0.80$ & $0.43-0.71$ & 242 & 242 \\
\hline $\mathrm{A} / \mathrm{C}$ & 0.56 & 0.43 & 6 & 46 & 107 & 82 & $0.44-0.88$ & $0.30-0.58$ & 242 & 208 \\
\hline $\mathrm{A} / \mathrm{E}$ & 0.74 & 0.55 & 6 & 59 & 107 & 80 & $0.62-1.00$ & $0.40-0.68$ & 242 & 209 \\
\hline $\mathrm{B} / \mathrm{C}$ & 0.40 & 0.40 & 6 & 33 & 83 & 82 & $0.22-0.50$ & $0.22-0.60$ & 242 & 208 \\
\hline $\mathrm{B} / \mathrm{E}$ & 0.60 & 0.58 & 6 & 48 & 83 & 80 & $0.50-0.75$ & $0.44-0.73$ & 242 & 209 \\
\hline $\mathrm{C} / \mathrm{E}$ & 0.44 & 0.43 & 6 & 35 & 82 & 80 & $0.31-0.63$ & $0.33-0.50$ & 208 & 209 \\
\hline $\mathrm{D} / \mathrm{E}$ & 0.35 & 0.35 & 6 & 28 & 80 & 80 & $0.06-0.75$ & $0.09-0.46$ & 200 & 209 \\
\hline $\mathrm{B} / \mathrm{D}$ & 0.32 & 0.31 & 6 & 26 & 83 & 81 & $0.09-0.47$ & $0.06-0.64$ & 242 & 200 \\
\hline $\mathrm{A} / \mathrm{D}$ & 0.35 & 0.26 & 6 & 28 & 107 & 81 & $0.18-0.46$ & $0.09-0.50$ & 242 & 200 \\
\hline $\mathrm{C} / \mathrm{D}$ & 0.26 & 0.26 & 6 & 21 & 82 & 80 & $0.09-0.46$ & $0.06-0.44$ & 208 & 200 \\
\hline
\end{tabular}

\section{Discussion}

The paired avalanche paths that met the 0.40 criterion every winter were adjoining, large, glacial cirques replete with multiple gully systems and starting points. These paths are unique due to the enormous quantities of blowing snow which are deposited in both starting zones; terrain at this site is favorable for frequent and large blowing-snow events. As a result, the paths produce more slab avalanches than any other pair in either sample. That this was the only pair out of nearly a thousand combinations which showed reasonably high conditional probabilities on a consistent basis is strong evidence against the practice of assigning a stability value to one path. given the occurrence of an avalanche on another. The plain fact is that the likelihood of joint natural events on specific paths is low on the average, and the large yearly variance of this probability is unacceptably high for index purposes. Before exploring the implications of this study, the reasons for these relatively low probabilities and high variance deserve comment. 


\subsection{Observational problems}

Föhn and others (1977) point out the significance of the observational problem in a discussion on model verification and there is general agreement among avalanche personnel that timing errors and the problem of missed observations are unlikely to be resolved in the foreseeable future. There is always the chance of assigning events to the wrong avalanche day, particularly when they occur near midnight, or during a prolonged storm. Visibility permitting, such occurrences are observed on a following day when observers estimate release times based on textural characteristics of the debris, the amount of new snow covering disturbed surfaces, or the degree of filling along avalanche crowns. In cases like this, it is likely that avalanches with similar age characteristics will be assigned to the same avalanche day, so the chances of lessening probabilities are minimized. While observational errors affect probability computations, experience has demonstrated that other factors are probably more important.

\subsection{Differences in avalanche frequency}

Large variations in avalanche frequency are common in avalanche samples and they appear to occur irrespective of proximity or physical similarity. The average annual frequency of natural slab avalanches in the samples varied from zero to 38 events per winter for the six-year period; one path produced 74 natural slab avalanches in a single winter. Frequency differences limit joint events and contribute to the low probabilities found in this study because paired paths of unequal frequency have low conditional probabilities. If one path occurs once per winter and another five times per winter, the maximum conditional probability is one in five, a ratio exceeded by only $10 \%$ of the pairs in this study. When one recalls that $80 \%$ of the 284 sampled paths were excluded from testing due to insufficient activity, it is apparent that index techniques using single paths are not likely to provide useful information in forecast situations.

\subsection{Other avalanche characteristics}

The likelihood of joint events is further restricted by other occurrence characteristics. Avalanches are rare events, there being more non-avalanche days in winter than avalanche days. When releases occur, only a portion of the sample is active. Bovis (1977) found that only a fraction of his avalanche sample was affected by slides on the majority of avalanche days. Our data support this conclusion and show that there are only two days per winter when more than $10 \%$ of the sample is active. On such days, it is rare to find avalanches on more than $20 \%$ of the paths. One extreme event produced slabs on $53 \%$ of the sample; the second worst case involved only $25 \%$ of the paths, so it is clear that most avalanche paths do not react to natural triggers on bad avalanche days. Absence of activity does not imply that the remainder of a sample is immune to artificial triggers, it just indicates that if avalanches are rare, joint events are rarer.

Data from ten years of observation on the large and diversified northern Colorado avalanche sample indicated that avalanches tend to fail repeatedly along earlier failure planes. This trend was noticed by Judson (unpublished), but available data at that time were too scanty to confirm the trend with much assurance. Since then it has been found that two or more repetitions per winter are common, given favorable weather and dry snow conditions. A plausible sequence for such events includes: increased trapping efficiency of blowing snow along a fresh crown, failure of the new deposits to bond to the old crown surface, and a resulting stress increase along smooth, older bed surfaces. In any event, the pattern diminishes the number of joint events 
because the controlling initial failures rarely occur on the same day, so future repetitions on various paths are out of phase.

\subsection{Joint events and degree of instability}

Probabilities in Table I result from average avalanche conditions and do not account for the areal extent or the magnitude of instability evidenced by the number of avalanche paths releasing on a given day. This aspect of the problem was addressed by separately ranking the 100 largest avalanche days in each sample and computing conditional probabilities among pairs for these episodes. Results indicate that the number of joint events is rather constant over the full range of avalanche conditions; conditional probabilities were no greater during avalanche cycles than they were on days with fewer avalanches.

\subsection{Group indexing}

Working forecasters are not limited to indexing with specified paths, but approach stability problems in a more general way by using reported activity as an index of group potential and integrating these reports with other data on avalanches, avalanche control, snowpack conditions, and weather. While this process cannot be simulated on computers, and testing single-path versus group response is expensive, a number of these relationships were tested by hand tabulations. The results in most cases were no better than those obtained with single-path runs, even though groups were stratified by similar aspect and terrain features. Additionally, some of the "single paths" were large enough to be considered a group by themselves. All that can be said about this extra work is that group indexing, whether done against single paths or with other groups, should be conducted with the same degree of caution as is advocated for single-path index work.

\subsection{Implications}

For the researcher who intends to develop a physical model for wide-area forecast applications, this study suggests the use of generalized or idealized terrain features rather than specific ones. Otherwise, problems arising from excessive detail defeat the initial purpose: we cannot model every feature of every path.

Implications for practicing forecasters and field personnel are less clear. Those who give snow safety advice to novices or issue bulletins for public use must adhere to the old maxim that presence of one or more fresh avalanches indicates instability, with the possibility that snow will release on other paths given a human trigger. The problem is that no-one can state what this likelihood is any better than one can specify which paths will avalanche. In most real-world situations, advice given in such situations states that all similar paths are dangerous. Conflicting with this assessment are numerous field reports of skiers successfully traversing avalanche areas in full view of fresh debris at times when forecasters believe avalanches are probable if not certain. The solution to this enigma will be sought for some time to come. If anything, results of this work indicate that stability information gained from avalanche events is less reliable than some may think. In fact there is reason to believe that the practice of confidently specifying that certain aspects or exposures are dangerous while others are not may be unjustified considering the present state of the art. 


\section{Conclusion}

A specific group of index paths will not simulate avalanche response in a large avalanche sample because avalanches respond in random fashion to point variations in snow properties. These variations are created by complex weather and terrain interactions, and by the occurrence of avalanches themselves. What appears to be a good index path one winter fails miserably the next, so index paths as such have little diagnostic value. The work indicates that when physical models are used for wide-area forecast problems, only generalized terrain features should be used. The random-failure characteristic is present over the full range of stability conditions. Presence of one or more fresh avalanches indicates point instability, which may be assessed in a general rather than a specific manner; it presents limited information about avalanche potential elsewhere and should be interpreted with caution.

MS. received 19 January 1982 and in revised form 19 May 1982

\section{REFERENCES}

Armstrong, R. L., and Ives, J. D., ed. 1976. Avalanche release and snow characteristics, San Juan Mountains, Colorado. University of Colorado. Institute of Arctic and Alpine Research. Occasional Paper No. 19.

Bovis, M. J. 1977. Statistical forecasting of snow avalanches, San Juan Mountains, southern Colorado, U.S.A. Journal of Glaciology, Vol. 18, No. 78, p. 87-99.

Föhn, P., and others. 1977. Evaluation and comparison of statistical and conventional methods of forecasting avalanche hazard, by P. Föhn, W. Good, P. Bois, and C. Obled. Journal of Glaciology, Vol. 19, No. 81, p. $375-87$.

Judson, A. 1970. A pilot study of weather, snow, and avalanche reporting for the western United States. Canada. National Research Council. Associate Committee on Geotechnical Research. Technical Memorandum No. 98, p. 123-34:

Judson, A. Unpublished. On the relative frequency of avalanches. [Unpublished manuscript, U.S. Department of Agriculture, Forest Service, Rocky Mountain Forest and Range Experiment Station, Fort Collins, Colorado, 1972.]

Judson, A., and others. 1980. A process-oriented model for simulating avalanche danger, by A. Judson, C. F. Leaf, and G. E. Brink. Journal of Glaciology, Vol. 26, No. 94, p. 53-63

Obled, C. 1970. Vers une prévision numérique des risques d'avalanches. Grenoble, Comité d'Études et de Documentation Nivologiques et Glaciaires. ([Contract Report] D. G. R. S. T. 69/02/094.) 